\title{
Effects of Grape Seedlings Intercropping with Floricultural Accumulator Plants on Different Fractions of Cadmium Content in Soil
}

\author{
Lisha Zhong ${ }^{1, a}$, Lijin Lin ${ }^{2, b}$ and Ming'an Liao ${ }^{1, c *}$ \\ ${ }^{1}$ College of Horticulture, Sichuan Agricultural University, Chengdu, Sichuan, China \\ ${ }^{2}$ Institute of Pomology and Olericulture, Sichuan Agricultural University, Chengdu, Sichuan, China \\ a645627089@qq.com, pllj800924@qq.com, Iman@sicau.edu.cn \\ ${ }^{*}$ Corresponding author. Lisha Zhong and Lijin Lin contributed equally to this work.
}

Keywords: Intercropping; Floricultural accumulator plants; Cadmium fractions; Grape seedlings

\begin{abstract}
The total amount of cadmium (Cd) in soil reflects the degree of pollution of the soil, but the bioavailability of $\mathrm{Cd}$ is mainly reflected by various fractions of it. In the experiment, four floricultural accumulator plants (Helianthus annuus, Cosmos sulphureus, Cosmos bipinnata and Impatiens balsamina) were used to intercrop with grape seedlings. The fractions of Cd in soil were studied after intercropping and the results showed that: The content of exchangeable $\mathrm{Cd}$ for the treatment of intercropping with $H$. annuus was $11.73 \%$ higher than the monoculture. The treatments of intercropping with $C$. bipinnata and I. balsamina can decrease the bioavailability of $\mathrm{Cd}$ significantly. Therefore, C. bipinnata and I. balsamina were suitable to intercrop with grape seedlings for the purpose of controlling Cd pollution in soil.
\end{abstract}

\section{Introduction}

Cadmium $(\mathrm{Cd})$ as the 6th toxic substance harmful to human health by the American Management Council (ATSDR) has become the major heavy metal pollutant in agricultural products in China [1]. The total amount of heavy metals in soil reflects the degree of pollution of the soil, but the bioavailability of heavy metals is mainly reflected by various fractions of heavy metals in soil [2]. There are five fractions of $\mathrm{Cd}$ (exchangeable, bound carbonates, bound to Fe-Mn oxides, bound to organic matter and residual) in soil according to Tessier [3]. The exchangeable $\mathrm{Cd}$ is the most active fraction and easily absorbed by plant, the residual $\mathrm{Cd}$ is inert fraction and hardily to be absorbed. $\mathrm{Cd}$ bound to carbonates and $\mathrm{Cd}$ bound to Fe-Mn oxides are sensible to the varieties of $\mathrm{pH}$, Eh in soil and easily reentered to soil [4]. The organic matter in soil can adsorb exchangeable Cd and convert it into $\mathrm{Cd}$ bound to organic matter to reduce the bioavailability of it [5]. Intercropping can adjust the basic properties of soil and change the rhizosphere environment, which can direct or indirect affect the fractions and the bioavailability of $\mathrm{Cd}$ in soil, then affect the absorption of $\mathrm{Cd}$ of the plant $[6,7]$. Therefore, the governance of $\mathrm{Cd}$ pollution can begin by reducing the bioavailability of $\mathrm{Cd}$ via intercropping. Different intercropping combination could lead to different changes to the bioavailability of $\mathrm{Cd}$. In the study, we used four floricultural accumulator plants (Helianthus annuus [8], Cosmos sulphureus [9], Cosmos bipinnata [10] and Impatiens balsamina [11]) to intercrop with grape seedlings, and research the effects on the fractions of $\mathrm{Cd}$ under the intercropping patterns then to find the suitable plant which can reduce the bioavailability of $\mathrm{Cd}$ in soil.

\section{Materials and Methods}

Materials. The seeds of four floricultural accumulator plants were collected from the farmland surrounding Chengdu Campus of Sichuan Agricultural University in March, 2016. The cultivar of grape is Kyoho cutting seedlings. The fluvo-aquic soil samples were collected from the experimental filed of Chengdu Agricultural and Forestry Academy in March, 2016.

Experimental Design. The experiment was conducted in Chengdu Campus of Sichuan Agricultural University from March to July, 2016. In March, the soil was air-dried, ground and passed through a $6.72-\mathrm{mm}$ sieve, then soaked it in the solution with $5 \mathrm{mg} / \mathrm{kg} \mathrm{Cd}$ (in the form of $\mathrm{CdCl}_{2} \cdot 2.5 \mathrm{H}_{2} \mathrm{O}$ ), and 
keeping the soil in the stage for 4 weeks to make the soil mixed well with $\mathrm{Cd}$. In April, mixed the soil again and then put $3 \mathrm{~kg}$ soil into every pot $(21 \mathrm{~cm}$ high, $20 \mathrm{~cm}$ in diameter). Three uniform seedlings $(25 \mathrm{~cm}$ in height) of grape were transplanted into each pot for monoculture and two of them for intercropping, respectively. One uniform seedlings of each floricultural accumulator plants ( $3 \mathrm{~cm}$ in height, and with 2 true leaves) were transplanted into each pot for intercropping (the seeds were put in the climate chamber to raise seedlings in March). The experiment consists of 5 treatments: monoculture of grape, grape intercropped with $H$. annuus, grape intercropped with $C$. sulphureus, grape intercropped with $C$. bipinnata and grape intercropped with I. balsamina. Three replicates were run for each treatment, and the experiment pots were arranged in a completely randomized design.

After 60 days, the soil from the rhizosphere in the corresponding pot was collected immediately while collecting the plant materials. All the soil samples were air-dried at room temperature then ground to pass through a 1-mm nylon sieve for analysis five fractions of Cd. Soil samples $(1.0 \mathrm{~g})$ were digested with $5: 1(\mathrm{v}: \mathrm{v}) \mathrm{HNO}_{3}: \mathrm{HClO}_{4}$ and measured by novAA 400P flame atomic absorption spectrophotometer (Analytik Jena, Germany) [12].

Statistical Analyses. Statistical analyses were conducted using statistical software of SPSS 17.0. Data were analyzed by one-way ANOVA with least significant difference at $5 \%$ confidence level.

\section{Results and Discussion}

The Content of Exchangeable Cadmium. Intercropping with different floricultural accumulator plants had different effects on the content of exchangeable Cd (Fig. 1). Intercropping with $H$. annuus and $C$. sulphureus increased the content of exchangeable $\mathrm{Cd}$ compared to monoculture of grape, and they were $11.73 \%(p>0.05), 9.18 \%(p>0.05)$ higher than the monoculture, respectively. On the contrary, intercropping with $C$. bipinnata and I. balsamina can decrease the content of exchangeable $\mathrm{Cd}$. The content of exchangeable $\mathrm{Cd}$ in the two intercropping patterns were $8.67 \%$ $(p>0.05)$ and $3.06 \%(p>0.05)$ lower than the monoculture, respectively.

The Content of Cadmium Bound to Carbonates. The intercropping patterns decreased the content of $\mathrm{Cd}$ bound to carbonates except the treatment of intercropping with I. balsamina (Fig. 2), but the increase or decrease was not significant. The content from highest to lowest was ranked as grape intercropping with $I$. balsamina $>$ monoculture of grape $>$ grape intercropping with $H$. annuus $>$ grape intercropping with $C$. bipinnata $>$ grape intercropping with $C$. sulphureus.

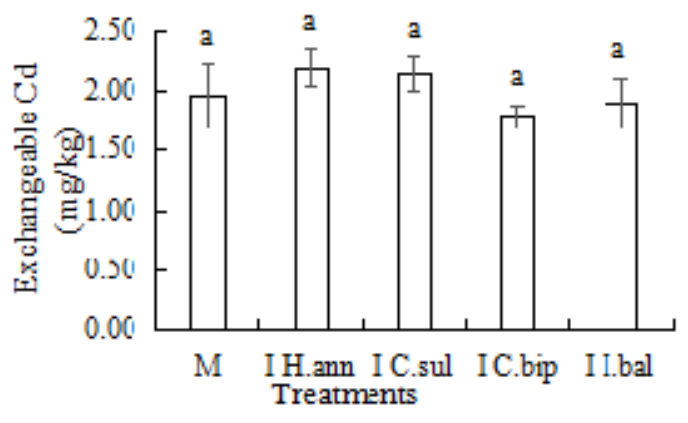

Fig. 1 The content of exchangeable $\mathrm{Cd}$ in soil. Different lowercase letters indicate significant differences based on one-way analysis of variance in SPSS 17.0 followed by the least significant difference test $(p<0.05) . \mathrm{M}=$ monoculture, I H. ann = intercropping with $H$. annuus, I C. sul = intercropping with $C$. sulphureus, I C. bip = intercropping with $C$. bipinnata, I I. bal = intercropping with $I$. balsamina.

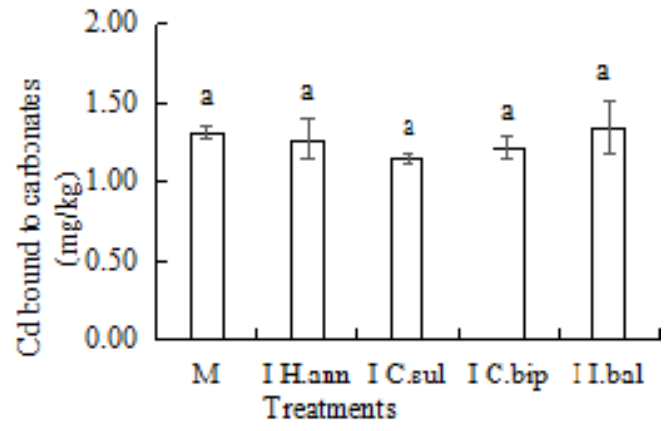

Fig. 2 The content of $\mathrm{Cd}$ bound to carbonates in soil. Different lowercase letters indicate significant differences based on one-way analysis of variance in SPSS 17.0 followed by the least significant difference test $(p<0.05)$. M $=$ monoculture, I H. ann = intercropping with $H$. annuus, I C. sul = intercropping with $C$. sulphureus, I C. bip = intercropping with $C$. bipinnata, I I. bal = intercropping with $I$. balsamina. 
The Content of Cadmium Bound to Fe-Mn Oxides. All the intercropping treatments increased the content of $\mathrm{Cd}$ bound to Fe- Mn oxides (Fig. 3). The content of Cd bound to Fe- Mn oxides for the treatment of intercropping with H. annuus was $23.53 \%(p<0.05)$ higher than monoculture and the other three treatments had no significant increase compared to monoculture.

The Content of Cadmium Bound to Organic Matter. Intercropping had a beneficial effect on increasing the content of Cd bound to organic matter (Fig. 4). All the intercropping patterns increased the content of $\mathrm{Cd}$ bound to organic matter and the treatment of intercropping with $C$. bipinnata had the best effect with $11.88 \%(p>0.05)$ higher than the monoculture.

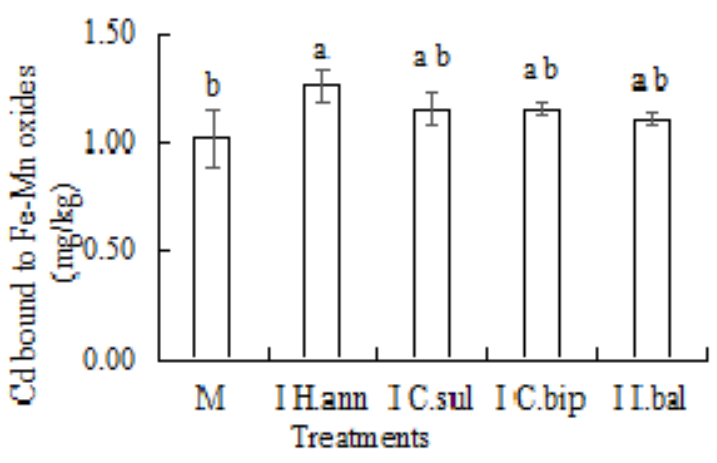

Fig. 3 The content of Cd bound to Fe-Mn oxides in soil. Different lowercase letters indicate significant differences based on one-way analysis of variance in SPSS 17.0 followed by the least significant difference test $(p<0.05)$. M $=$ monoculture, I H. ann = intercropping with $H$.

annuus, I C. sul = intercropping with $C$. sulphureus, I C. bip = intercropping with $C$. bipinnata, I I. bal = intercropping with $I$. balsamina.

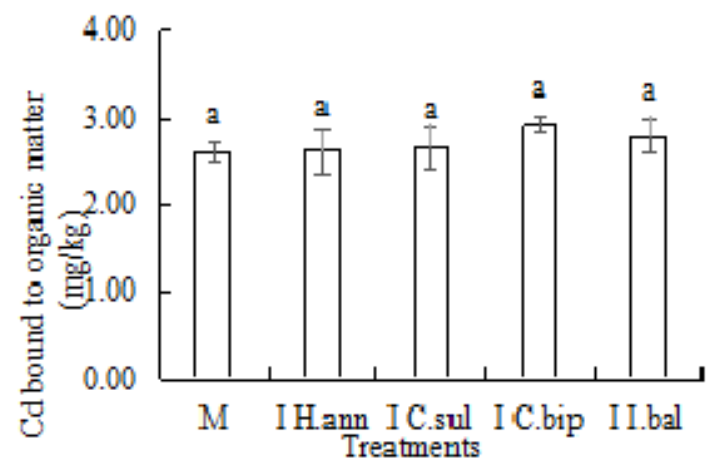

Fig. 4 The content of $\mathrm{Cd}$ bound to organic matter in soil. Different lowercase letters indicate significant differences based on one-way analysis of variance in SPSS 17.0 followed by the least significant difference test $(p<0.05) . \mathrm{M}=$ monoculture, $\mathrm{I} \mathrm{H}$. ann $=$ intercropping with $H$. annuus, I C. sul = intercropping with $C$. sulphureus, I C. bip = intercropping with $C$. bipinnata, I I. bal = intercropping with I. balsamina.

The Content of Residual Cadmium. All the intercropping patterns increased the content of residual $\mathrm{Cd}$ in soil obviously. Sorting the content of residual $\mathrm{Cd}$ of each treatment from highest to lowest: intercropping with $I$. balsamina $>$ intercropping with $C$. bipinnata $>$ intercropping with $H$. annuus $>$ intercropping with C. sulphureus (Fig. 5). In particular, the content of residual Cd for the treatments of intercropping with I. balsamina and C. bipinnata were $44.12 \%(p<0.05)$ and $35.29 \%$ $(p<0.05)$ higher than the monoculture.

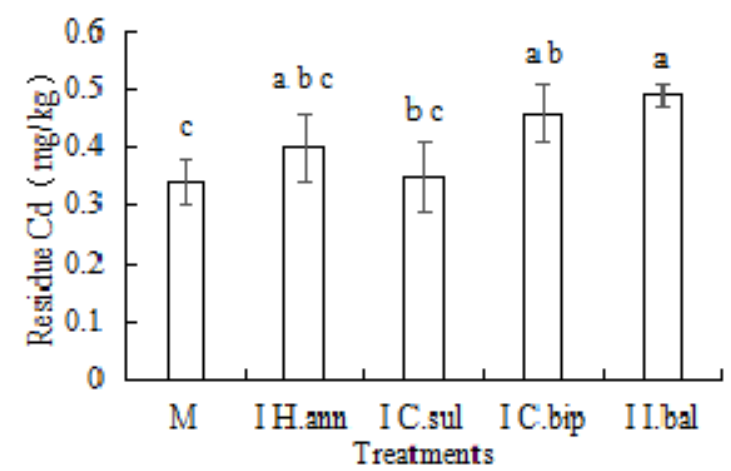

Fig. 5 The content of residual Cd in soil. Different lowercase letters indicate significant differences based on one-way analysis of variance in SPSS 17.0 followed by the least significant difference test $(p<0.05)$. M monoculture, I H. ann = intercropping with $H$. annuus, I C. sul = intercropping with $C$. sulphureus, I C. bip = intercropping with $C$. bipinnata, I I. bal = intercropping with I. balsamina . 


\section{Conclusions}

According to the experiment, we got the following conclusions: Intercropping with different floricultural accumulator plants had different effects on the fractions of $\mathrm{Cd}$ in soil. Intercropping with $H$. annuus increased the content of exchangeable $\mathrm{Cd}$ in soil significantly $(11.73 \%$ higher than the monoculture). Grape intercropping with C. bipinnata and I. balsamina decreased the content of exchangeable $\mathrm{Cd}$ and increased the content of $\mathrm{Cd}$ bound to organic matter and residual $\mathrm{Cd}$, and then the bioavailability of $\mathrm{Cd}$ decreased. Therefore, $H$. annuus was not suitable to intercrop with grape seedlings for the purpose of controlling the Cd pollution in soil. C. bipinnata and I. balsamina can be used in vineyards to decrease the bioavailability of $\mathrm{Cd}$ and protect the grape from $\mathrm{Cd}$ pollution.

\section{Acknowledgements}

This work was financially supported by the Application Infrastructure Project of Science and Technology Department of Sichuan Province (2016JY0258).

\section{References}

[1] B. Song, D. Gao, T.B. Chen, Z.C. Huang, Y.M. Zhen, M. Lei, G.D. Zhen, J. Yang and X.Y. Liao: Journal of Environmental Science Vol. 26(2006), p. 1343.

[2] Z.J. Yang, Z.G. Zhang, J.Y. Cao, J. Liu and A.M. Han: Journal of Huaiyin Institute of Technology Vol. 3(2003), p. 85.

[3] A. Tessier, P.G.C. Campbell, M. Bisson: Analytical Chemistry Vol. 51(1979), p. 844.

[4] J.L. Li, H.M. Song: Environmental Science Trends Vol. 1(2003), p. 24.

[5] S. Gao, J.B. Chen, G. Wang: Plant Nutrition and Fertilizer Science Vol. 1(2003), p. 102.

[6] G.C. Daellenbach, P.C. Kerridge, M.S. Wolfe: Agricultural Ecosystems and Environment Vol. 105(2005), p. 595.

[7] G. Agegnegu, A. Ghizaw, W. Sinebo: European Journal of Agronomy Vol. 25(2006), p. 202.

[8] J. Zou, P. Xu, X. Lu, W. Jang and D. Liu: Pakistan Journal of Botany Vol. 40(2008), p.759.

[9] L.J. Lin, Q.Q. Ma, J. Shi, J. He, C.C. Zhong, J.J. Huang, K. Wen and M.A. Liao: Journal of Soil and Water Conservation Vol. 3(2016), p. 141.

[10]J.J. Huang, Z.B. Yang, J.H. Li, M.A. Liao, L.J. Lin, J. Wang, Y.X. Yang, D. Liang and H. Xia: Chemistry and Ecology Vol. 33(2017), p. 1.

[11]Z.F. Wang, K.W. Huang, H.S. Lian and L.J. Lin: Northern Horticulture Vol. 7(2018), p. 66.

[12]J.C. Ai, N. Li and N. Wang: Journal of Agro-Environment Science Vol. 32(2013), p.491. 